\title{
Da comunicação científica à divulgação'
}

\author{
From scientific communication to popularization
}

Palmira Moriconi VALERIO²

Lena Vania Ribeiro PINHEIRO ${ }^{3}$

\section{RESUMO}

A comunicação científica, o periódico científico e o aumento do acesso à informação e comunicação pelas redes eletrônicas introduzem a discussão da relação da comunicação com a divulgação científica. A ampliação da audiência proporcionada pela Internet e a maior visibilidade da ciência com as versões eletrônicas dos periódicos científicos são exploradas e é discutida a aproximação entre público especializado e não-especializado, bem como a possível convergência de audiências a partir da comunicação em rede eletrônica e das tecnologias de informação e comunicação - TICs. Conceitos, características, funções da comunicação e da divulgação científi$\mathrm{ca}$, bem como aspectos históricos da formação do público e da ciência, remetem aos principais autores dessas duas áreas e a re-pensar a divulgação da ciência e a "ciência pública" para além dos muros acadêmicos. Pressupostos teóricos fundamentam o caráter público da ciência e a natureza transformadora da informação, enquanto aspectos técnicos, mostram o campo para novas tecnologias de informação e comunicação, transferência de informação e interatividade entre público acadêmico e não acadêmico, sugerindo tecnologias como agentes de mudança de cultura, tendo a Sismologia como área de demonstração.

Palavras-chave: tecnologias de informação e comunicação - TICs; comunicação científica; divulgação científica; periódico científico eletrônico; ciência pública; visibilidade da ciência.

\begin{abstract}
Scientific communication, scientific journals and a more comprehensive access to information and communication on the Internet establish a debate over the connection between scientific communication and divulgation. Exploring the audience expansion enabled by the Internet and the greater science visibility due to the Internet versions of scientific journals, entails a discussion on bringing the specialized and non-specialized public closer, and their possible convergence as a result of intercommunication on the Internet, and the information and communication technologies - ICTs. Concepts, characteristics, the applicability of communication and science divulgation as well as the historical aspects of science and audience development, bring to mind the most important specialists in these two areas: It is necessary to rethink science popularization and "public science" beyond the academic walls. Theoretical presuppositions substantiate the public component of science and the transmutable nature of information. The technical features reveal the field for new information and communication technologies, passing on information and interactivity between the academic and non-academic audience, which put forth technology as a determinant point for cultural changes, having Sismology as the demonstration area.
\end{abstract}

Keywords: information and communication technologies - ICTs; scientific communication; scientific divulgation; scientific electronic journal; public science, visibility of science.

1 Artigo proveniente de parte da tese: VALERIO, P.M. Periódicos científicos eletrônicos: possível aproximação de públicos e novas perspectivas de comunicação e divulgação para a ciência. Rio de Janeiro, 2005. 210f. Tese (Doutorado) Instituto Brasileiro de Informação em Ciência e Tecnologia (IBICT), convênio com a Universidade Federal do Rio de Janeiro, 2005.

2 Financiadora de Estudos e Projetos (FINEP). Praia do Flamengo, 200, $9^{\circ}$ andar, 22210-020, Rio de Janeiro, RJ, Brasil. Correspondência para/Correspondence to: P.M. VALERIO. E-mail: <moriconi@finep.gov.br>.

3 Instituto Brasileiro de Informação em Ciência e Tecnologia (IBICT). Rua Lauro Muller, 455, $5^{\circ}$ andar, Botafogo, 22290-160, Rio de Janeiro, RJ, Brasil. E-mail: <lenavania@ibict.br>.

Recebido em 21/6/2007 e aceito para publicação em 5/3/2008. 
INTRODUÇÃO

Novas descobertas e invenções revolucionaram, em todas as épocas, os padrões de comportamento e o acesso ao conhecimento nas sociedades. A imprensa, por exemplo, provocou mudanças radicais na cultura, permitindo que o conhecimento, cativo de sábios e eruditos, chegasse a um público mais amplo. A Revolução Industrial, igualmente, representou um conjunto significativo de novas formas de agir, marcando a evolução dos mercados e o desenvolvimento da ciência e da técnica. A chegada do século XX foi acompanhada de impulso sem precedente no conhecimento e no desenvolvimento tecnológico, em um cenário de grandes guerras que definiu o desenvolvimento de indústrias, a ampliação do mercado e consumo de novos produtos, de bens materiais e culturais, tangíveis e intangíveis, imprimindo novos comportamentos na sociedade.

A ciência ganhou mais espaço e com ela a produção do conhecimento, refletida no crescimento da literatura e desenvolvimento de técnicas e especializações de áreas. A necessidade de organizar o acesso e a oferta de informação se faz presente, propiciando o surgimento de nova área do conhecimento, a qual passa a preocupar-se com o fenômeno conhecido como "explosão da informação", na expressão cunhada por Bush (1945), coordenador de um trabalho de seis mil cientistas americanos na Segunda Guerra Mundial, no esforço de aplicação da ciência nas atividades da guerra.

Instituição circunscrita ao espaço de produtores, disseminadores e daqueles que usufruem os resultados da pesquisa científica, a ciência é surpreendida por novos fluxos de informação. A Internet, nova protagonista desse espetáculo, permitiv a milhares de novos usuários da informação trafegar na grande rede a cada instante, ampliando exponencialmente o público em potencial ao acesso da comunicação e da informação.

Novos avanços na ciência e tecnologia brindamnos com a comunicação eletrônica que, por sua vez, avança para conexões em redes, ligando espaços virtuais infinitos, aproximando territórios e indivíduos.
Práticas estabelecidas são alteradas e esse novo meio de comunicação em rede invade o cotidiano das pessoas, provocando diferentes estilos de relacionamento, impulsionando expressivamente, como conseqüência, a espiral dos saberes.

O conhecimento incorporado pela literatura científica, por meio dos periódicos científicos, é também disponibilizado nas redes eletrônicas. Versões eletrônicas dos periódicos científicos impressos, bem como periódicos científicos exclusivamente eletrônicos, são cada vez mais comuns na grande rede, cópias fiéis, espelhos ou não, do formato em papel, proporcionando o aumento da visibilidade da ciência e ampliando a audiência. $O$ mundo acadêmico e o conhecimento científico legitimado pelo sistema formal de comunicação da ciência, cuja expressão máxima é o periódico científico, passam a conviver com uma forma de comunicação e informação diferente que extrapola o convencional, rompendo fronteiras "re-conhecidas", ampliando a audiência e alcançando outros públicos, atingindo a audiência da alçada da divulgação científica ${ }^{4}$, fazendo uma grande interseção com públicos não especializados.

A interação da divulgação científica com a comunicação foi apontada em artigo de Pinheiro, referente à pesquisa sobre o processo de comunicação científica de comunidades científicas brasileiras em redes eletrônicas, da qual as autoras participaram. Especificamente, a pesquisa visou a verificar a função e a importância dos diversos recursos eletrônicos na comunicação científica em rede, na sua interdependência e relação com canais de comunicação formais e informais, tradicionais e convencionais. Entre os resultados, foi visto: "Um dos primeiros fenômenos observados, decorrente da Internet, foi a aproximação entre comunicação científica (de cientistas para cientistas) e divulgação científica [...]" (Pinheiro, 2003).

Nossa argumentação é de que as informações científicas, disponibilizadas eletronicamente, possam vir a desempenhar novo papel, além da comunicação exclusivamente dirigida à audiência acadêmica. Supomos haver aproximação, ou mesmo convergência de públicos, acadêmico e não acadêmico, em relação à literatura científica publicada eletronicamente, quer seja em sites ou periódicos científicos eletrônicos, 
conformando uma nova composição de audiência para a ciência. Essa aproximação ou convergência de públicos - como nos parece adequado denominar -, graças às redes eletrônicas, permite, por outro lado, maior visibilidade e reconhecimento da importância da ciência, favorecendo a conscientização da sociedade em relação à maior participação na formulação de políticas públicas de ciência e tecnologia para o desenvolvimento.

\section{COMUNICAÇÃO CIENTÍFICA}

Ao examinarmos a possível aproximação ou ampliação de audiência do principal veículo de comunicação de ciência, a partir das novas tecnologias de rede eletrônica, passamos a destacar os principais autores e questões relativas, primeiramente, à comunicação e, posteriormente, à divulgação de ciência.

Para tanto, devemos esclarecer primeiramente que, enquanto a comunicação científica é a forma de estabelecer o diálogo com o público da comunidade científica - comunicação entre os pares -, a divulgação científica visa à comunicação para o público diversificado, fora da comunidade científica.

Garvey e Griffith (1979), ao observarem que o crescimento da literatura nos arquivos de periódicos, da área de Psicologia científica americana, não acompanhava o número de psicólogos formados pelas universidades, evidenciaram a importância da comunicação na ciência, a qual se constitui em um sistema social. Descobriram que a comunicação é um processo que se inicia com a pesquisa e termina com as descobertas incorporadas ao conhecimento científico, sendo a informação parte inseparável da pesquisa.

A Comunicação Científica é definida por esses autores (Garvey; Griffith, 1979, p.127-163) como o conjunto de atividades associadas à produção, disseminação e uso da informação. Na fase da pesquisa ocorre a geração da informação e a disseminação se dá pela transferência da informação por meio de canais de comunicação heterogêneos, os quais podem ser formais ou informais, orais ou escritos.

A distinção entre formal e informal é esclarecida na definição de Meadows (1999, p.7): o periódico científico é o canal formal da ciência, constituindo-se na expressão máxima legitimadora da autoria das descobertas científicas. Os canais informais são formas efêmeras de comunicação, por ficarem à disposição de um público limitado por pouco tempo. Entre os meios de comunicação orais, estão as conversas, os encontros científicos, os colóquios e as conferências, bem como as comissões científicas e técnicas. Entre os meios escritos, estão os relatórios de pesquisa, relatórios técnicos, teses e dissertações, boletins, pré-publicações (pre-prints), anais (proceedings), artigo de periódico e o próprio periódico científico (Garvey; Griffith, 1979, p.127-163). Meadows inaugurou um novo ciclo de destaque para a comunicação de ciência, ao enfatizar a importância da comunicação, e ao deixar claro que a comunicação é tão vital quanto a própria pesquisa.

Em um outro sentido, temos que o internacionalismo é próprio da natureza da ciência, a qual busca alcançar público mais amplo possível, a fim de atingir o seu objetivo de difundir o conhecimento (Ziman, 1979).

Na obra intitulada Public knowledge: the social dimension of science, publicada, em sua primeira edição, em 1968, John Ziman (1979) dedica-se a estudar e a escrever o processo interno de relações sociais da ciência, tornando-se referência obrigatória para a Ciência da Informação e Comunicação Científica.

Segundo Ziman, (1979, p.92), "os critérios de prova em ciência são públicos e não privados e [...] o interesse dos cientistas está voltado para a criação de um consenso". $O$ consenso é dado, primeiramente, pela aceitação de uma base lógica da teoria, ou seja, a teoria é passível de aceitação pública porque é sólida e sem contradições; em segundo lugar, pela concepção e aceitação do método científico que permite comprovação por meio da possibilidade da repetição do experimento. Essa concordância dá o caráter público da ciência para Ziman (1979, p.83): "uma grande descoberta científica não passa a existir, apenas, por força da autoridade moral ou do talento literário do seu criador, e sim pelo seu reconhecimento e sua apropriação por toda a comunidade científica". O internacionalismo da ciência, de acordo com Ziman assim como o princípio mertoniano de socialização do conhecimento -, no nosso ponto de vista, entretanto, adquire nova dimensão com as redes eletrônicas que surpreendem a todos com novos e infinitos fluxos de informação. 


\section{DIVULGAÇÃO CIENTÍFICA}

Quanto aos princípios que regem a divulgação científica, a literatura indica que as denominações divulgação científica, vulgarização científica e popularização da ciência equivalem-se, e cada expressão é adotada conforme o país e a época em que esta área é estudada (Nelkin, 1995; Jacobi; Schiele, 1988 apud Massarani, 1988, p. 11).

Para Reis e Gonçalves (2000, p.7-69)5 , o interesse do público por assuntos da ciência cresce com a Revolução Industrial, assim como a demanda pelo aumento da escolarização, associado a conhecimentos básicos de ciência. Só no século XX, entretanto, em que o desenvolvimento científico e tecnológico foi significativo, os jornais incluem as novidades da ciência em suas matérias. Por outro lado, o crescimento de cursos universitários que se verificou na segunda metade do século XX propiciou o incremento no quantitativo de jornalistas e bacharéis da Comunicação Social, faculdade que abrigou o curso de Jornalismo a partir da reforma universitária de 1961. A divulgação científica, por seu turno, começa a ocupar espaço por meio da organização de jornalistas e profissionais relacionados a essa área, os quais são movidos pela necessidade de informar às pessoas comuns as novidades nas áreas da ciência e os benefícios das descobertas científicas.

Podemos estender à divulgação científica as funções básicas do jornalismo científico, de acordo com Frota-Pessoa (1988), pesquisador e estudioso dessa área. Segundo o autor, o jornalismo científico cumpre seis funções básicas: informativa, educativa, social, cultural, econômica e político-ideológica (Kreinz, 1998, p.21-23 apud Nunes, 2003).

Vale observar que essa área está em franco crescimento e que o público interessado nos assuntos de ciência vem crescendo e ajudando a consolidar nova configuração nas formas de apropriação do conhecimento, o que pode ser constatado pela verdadeira explosão no número de canais de divulgação científica, quer pela promoção de eventos, criação de museus ou espaços para a ciência, ou ainda pela criação de inúmeros boletins e jornais eletrônicos.
Revistas como Ciência e Cultura e Ciência Hoje, já tradicionais, e as mais recentes ComCiência, Superinteressante e, bem mais recente, a edição brasileira da Scientific American, revelam, no Brasil, o crescente interesse pela ciência por parte de outros públicos que não o da comunidade científica. No exterior, as revistas Nature e Science, bem como a própria Scientific American, desfrutam de confortável prestígio internacional, sendo referências para revistas de divulgação e de comunicação de ciência na Inglaterra e nos EUA. A francesa La Recherche estende seu prestígio para além de suas fronteiras, tendo leitores tradicionais também no Brasil.

O número crescente de sites especializados conectando pessoas e países por meio da web, e as evidências do aumento do acesso à informação por maior fatia da população mundial, a quantidade de documentos gerados e disponibilizados em rede ${ }^{6}, 0$ crescente aumento do número de revistas científicas on-line ${ }^{7}$ observado nos últimos anos, e as iniciativas de acesso livre (Open Access) levam-nos a algumas reflexões relacionadas à comunicação, à divulgação científica e ao acesso à informação e ao conhecimento científico e tecnológico, à participação, nesse sistema, de novos públicos provenientes, ou não, de regiões ou países fora do alcance dos meios formais do sistema de comunicação científica.

A comunicação de ciência e sua popularização parecem-nos entrelaçadas em seus processos comunicacionais, a partir das novas tecnologias de comunicação em rede eletrônica. Nesse sentido, um público ampliado, com características de uma audiência constituída de pessoas interessadas em ciência, fora da comunidade científica, pode-se configurar numa nova composição de público, ou na interseção com a audiência própria da divulgação científica.

\section{ALGUNS DOS PRESSUPOSTOS TEÓRICOS E TÉCNICOS PARA A CONVERGÊNCIA DE PÚBLICOS}

Os diferentes significados da construção do debate acadêmico on-line que se relacionam com o

5 Série editada por Gloria Kranz e Crodowaldo Pavan, inclui aula de Gonçalves constituída, segundo a autora, por "excertos da vastíssima obra do prof. José Reis" por ela compilados, tanto que são reproduzidos entre aspas.

6 A AlIM - International Association for Information and Image Management International, associação americana sobre gerenciamento da documentação, prevê que a quantidade de informação duplicará a cada onze horas em 2010.

7 O SciELO, por exemplo, em 2003, incorporou 15 novos periódicos eletrônicos no seu banco, tendo rejeitado 24 e submetido à reavaliação mais quatro. 
campo da ciência, tecnologia e sociedade, são focalizados por Hert (1997) para mostrar como as interações científicas são reproduzidas na nova mídia, enquanto, simultaneamente, alguns usuários tiram vantagens das novas possibilidades oferecidas por esse meio.

Não sendo o objeto principal de sua investigação, o autor deixa de lado a questão do público ou de uma nova comunidade latente, e admite que a informação científica possa ser originada e transferida por meio de novos formatos. É também cauteloso quanto à afirmação de que a extensão dessas novas tecnologias possa afetar o conteúdo da informação científica e substituir a mídia tradicional no processo de transformação da informação em conhecimento (Hert, 1997). Porém, no âmbito de nosso foco, toma vulto uma de suas conclusões sobre a existência de uma comunidade científica mais larga, heterogênea, com opiniões divergentes, e que não aparecem no público tradicional da ciência (Hert, 1979).

Em 1916, Paul Otlet, autor do imaginário Palais Mundaneum, já falava da natureza transformadora da informação. Otlet acreditava que era preciso preparar a opinião pública, criar nas massas uma atitude mental, um entendimento claro do processo do conhecimento por meio da informação (apud Ricusset-Lemarié, 1998). Ainda que não seja abordado especificamente o termo divulgação científica na obra de Otlet, depreendemos ser essa sua preocupação ao trabalhar a organização da informação para que o grande público alcance a transcendência para o conhecimento, conhecimento que seria fonte de mudança e transformação social.

Considerando que as tecnologias de informação e comunicação eletrônicas podem proporcionar maior acesso à informação e ao conhecimento não somente a um público especializado, mas também a outro, mais amplo, tomamos por base essas novas tecnologias e o campo fértil oferecido pelas infovias à exploração do ambiente eletrônico, assim como novos modos de exercer a comunicação de ciência, como, por exemplo, a eliminação de determinadas etapas e modificação de algumas práticas consagradas no ofício de editoração dos periódicos científicos. Essas transformações fazem-nos acreditar em uma maior aproximação entre os públicos da comunicação e divulgação científica. Se, de fato, modificações significativas estão em curso, é fato também que existe um campo aberto para o surgimento de novas tecnologias e oportunidades em relação aos meios de comunicação e transferência de informação entre o público acadêmico e o não acadêmico.

No âmbito da comunicação de ciência, a aplicação dessas inovações e as oportunidades que com elas se abrem, permitem-nos inferir haver um estreitamento na distância entre aqueles que fazem a ciência e aqueles que a absorvem, ou aqueles que se beneficiam dos produtos desenvolvidos, a partir dos resultados das pesquisas, incorporados em suas vidas. Ou, ainda, na maior interação dos cientistas com o público, público entendido como o conjunto de indivíduos, na sociedade, que percebem os benefícios da ciência e podem demandar por novos conhecimentos e aplicações.

Assim compreendido, abrem-se perspectivas de novos caminhos para explorar as formas de contribuição dos periódicos científicos eletrônicos, no sentido de minorar e/ou eliminar barreiras existentes entre países desenvolvidos e aqueles em desenvolvimento. A ciência reuniria novas condições para atingir seu caráter universal em sua plenitude, pela contribuição de pesquisas oriundas de regiões ou comunidades com baixa perspectiva de participação no mainstream e viabilizaria resultados de pesquisas desconhecidas, contribuindo para elevar o nível do conhecimento e das condições de vida de nações e povos menos privilegiados. A realidade, entretanto, mostra que a assinatura de periódicos eletrônicos é dispendiosa e a alternativa que vem sendo pensada e implementada, que pode recuperar o ideal otletiano, está consubstanciada no movimento para acesso livre (Open Access), já mencionado. ${ }^{8}$

\section{MUDANDO A CULTURA: A INTERATIVIDADE POSSÍVEL NO MEIO DIGITAL}

Possíveis mudanças nos modelos dos meios de comunicação na rede são discorridas por Alvarez (2002). Em seu artigo, questiona que, se existem, devem mudar também os papéis entre emissor e receptor, e estabelecer maior participação desses últimos, alterando

\footnotetext{
8 Embora as autoras reconheçam as diferenças conceituais e de tradução para Open Access (acesso livre e/ou acesso aberto), neste artigo tal questão não é abordada por não ser seu objeto principal e merecer maiores discussões.
} 
o atual esquema de transmissão da informação, mas não de comunicação - ressalta ela -, a qual pressupõe troca, intercâmbio. A autora advoga que, para a construção de novas propostas nos meios digitais, a interatividade joga um papel fundamental. Alvarez questiona também os papéis das empresas desses meios que não estão interessadas em seguir o que as tecnologias proporcionam para mudar o modelo, e sim reproduzir o que já existe em papel, uma cópia piorada no meio digital. Reportando-se a Jordi Bernat (2002), destaca que a função dos meios que incursionam na rede terão que ser entendidos no adequado quadro de evolução e desenvolvimento tecnológico, os quais hoje são muito mais informadores do que propiciadores do processo de comunicação.

Outro aspecto da mudança no meio digital diz respeito à competitividade das idéias. Alvarez (2002, p.4) situa o novo mundo digital altamente competitivo por idéias e informação, citando Beckett, Gillenwater, Kirby e Olivo (2000, p.61): "[...] a competência pela sobrevivência dessas idéias muda em sua natureza: se antes o importante era distribuir o maior número de cópias individuais, agora o objetivo é fazer apenas uma cópia, porém mais acessível e com maior freqüência de uso". A autora alerta para o papel mais ativo do receptor na interatividade com o emissor, reafirmando a troca e o intercâmbio, próprios da ação de comunicação.

Um dos poucos artigos que reflete a comunicação de ciência sob o aspecto sócio-cultural provém de Cetto (2001), da Universidade do México, na Conferência sobre publicações eletrônicas promovida pela UNESCO. Essa pesquisadora sugere novas formas de pensar, a partir dos avanços da tecnologia e suas aplicações, como agentes de mudança da cultura, enfocando as alterações provocadas na cultura material sem rebatimento na cultura imaterial, que seriam os valores e normas na sociedade. Cetto (2001) evidencia que as tecnologias de comunicação não estão necessariamente sendo utilizadas para atender às necessidades de comunicação da ciência e que a relação ciência e sociedade deve ser repensada, já que existe um enorme público fora da comunidade científica e uma nova cultura formandose pela absorção das tecnologias de rede, a que denomina de literatos-internet:

Fora algumas exceções, a comunidade científica não tem tomado para si estas mudanças no sentido de comunicar-se com as centenas ou milhões de pessoas que dia-a-dia conectam-se na rede e navegam em busca de informação, ou somente para aprender ou entender, descobrir... ou simplesmente distrair-se (Cetto, 2001, p.24).

Segundo a autora, inclusive as comunidades médica, biomédica e bio-informática têm sido exceção nessa tarefa, oferecendo mais de 10 mil sites nos EUA, com oferta de um expressivo conjunto de serviços (Cetto, 2001).

Para confirmar sua teoria, a mesma autora faz uma breve pesquisa nas páginas da web dedicadas à ciência em idioma espanhol, usando essas duas palavras como chave e o mecanismo de busca Altavista. Um total de 345 mil páginas foi encontrado - em contraste com 15 milhões de páginas sobre ciência em idioma inglês - a maioria delas hospedadas na Espanha, um pouco em países latino-americanos e EUA. Dos 100 primeiros itens na lista, somente 29 foram selecionados como periódicos com conteúdo científico, sendo o restante sem esse atributo (Cetto, 2001).

Suas considerações induzem à interpretação de que as ferramentas oferecidas pela tecnologia estão disponíveis para que a comunicação de ciência aconteça para além da comunidade científica, para um público ampliado. Assim sendo, não apenas a cultura material (artefatos tecnológicos) pode ser modificada, mas também a cultura não material, ou cultura, propriamente dita. Em outras palavras, a sociedade dispõe de condições para avançar e repensar valores éticos a partir do conhecimento e da assimilação do avanço da ciência e da tecnologia. As ferramentas estão disponíveis, é só usá-las (Cetto, 2001).

Ainda é Cetto (2001) que argumenta sobre a cultura, sugerindo repensar a questão da popularização da ciência e, de forma mais audaciosa, a amplitude do entendimento de Ziman (1979) em relação à "ciência pública" para além dos muros acadêmicos:

As novas tecnologias abrem uma verdadeira e valiosa oportunidade para estabelecer diferentes modos de comunicação, não somente com nossos padrões, mas também com outros stakeholders nos empreendimentos de ciência. Estes empreendedores da ciência nos convidam a revisar a abordagem, os conceitos e prá- 
ticas da "popularização de ciência", entendimento de "ciência pública", etc. e redesenhálos para estabelecer as muitas necessidades de conexões reais - como oposto ao virtual - entre ciência e sociedade (CETTO, 2001, p. 26).

\section{COMUNICAÇÃO E DIVULGAÇÃO CIENTÍFICA: PÚBLICOS CONVERGENTES?}

Inspiramo-nos na tragédia, originada no teatro grego, para demonstrar como a divulgação científica e a comunicação científica aproximam-se e complementam-se. Especialmente por envolver muitas vítimas, a palavra tragédia chegou à modernidade com o sentido de desastres, de catástrofes, e a mídia explora essas catarses e, assim, vende seus produtos.

A divulgação de fatos de impacto, especialmente sobre sexo, violência e tragédias são as notícias que mais vendem, em detrimento das notícias de ciência e tecnologia, que não passam de $6 \%$ na cobertura da imprensa do Rio de Janeiro e São Paulo (Melo, 1987).

Pelo lado da ciência, a mídia, após a divulgação de determinada tragédia, tem oportunidade de explorar suas causas, divulgando explicações dos especialistas, ao mesmo tempo em que, num movimento complementar, cumpre o papel da comunicação científica como se depreende dos relatos a seguir.

Em artigo publicado na Nature, Schweig, Gomberg, Bodin, Patterson e Davis (2001) descrevem a experiência obtida a partir de um abalo sísmico ocorrido em Gujarat, na Índia, que proporcionou o avanço do conhecimento na área de Sismologia e demonstra a aproximação entre as áreas de jornalismo científico e comunicação de ciência por meio da Internet. $O$ estudo mostrou como a lista de discussão regional facilitou respostas comprobatórias à teoria, anteriormente formulada em evento internacional. A rapidez da Internet, mais especificamente, a lista de discussão eletrônica, facilitou a coordenação de uma resposta científica, a comunicação de resultados e a troca de idéias na área, visto que se tem muito a aprender cientificamente em termos de sismologia, geologia e engenharia estrutural, devido às respostas imediatas que se obtêm, depois de ocorrido o fenômeno.

A área de Sismologia parece-nos propícia à demonstração de nossa proposta, conforme visto no estudo anterior e no próximo caso, do tsunami. A tragédia, conseqüência de um maremoto, que provocou a morte de cerca de 300 mil pessoas, na Ásia, nos últimos dias de 2004, põe em evidência, mais uma vez, o que pode ser visto como a aproximação entre a comunicação científica e a divulgação. Primeiramente, pelo impacto da notícia, posteriormente, pela divulgação da informação científica e, por fim, pela importância das comprovações científicas na busca de solução para problemas de ordem pública. Com o título "Tsunami disaster: a failure in science communication", o editorial de 17 de janeiro da Scidev.net (2005), ao comentar o desastre que provocou a tragédia divulgada ao mundo em poucos instantes, relata como foi possível salvar do efeito tsunami inúmeras vidas. O fato ocorreu em uma vila de pescadores em Nallavadu, na costa nordeste da Índia, no estado de Tamil Nadu. Essa vila, assim como outras, faz parte do projeto da Swaminathan Research Foundation, sendo beneficiada por um pequeno centro de telecomunicações ligado à Internet, prestando serviços de prevenção quanto a fenômenos geológicos, evitando situações de perigo. Nesse fatídico dia, o responsável pelo centro de telecomunicações se ausentou para ir a Cingapura, justamente, procurar novos dados sobre recente terremoto ocorrido na Indonésia. Ciente do iminente perigo, ainda fora da vila, mandou a família abandonar o local e avisar a outros habitantes do perigo de inundação pelas ondas gigantes. Imediatamente, a notícia correv e houve tempo para que o centro de telecomunicações desse o alerta para a população que se salvou a tempo. Em função da eficiente articulação da informação, da comunicação científica e da divulgação - enfatiza o editorial - coordenadas na prestação de um serviço público, foram salvas cerca de 500 famílias. Nos outros locais o efeito tsunami, ao contrário, causou a tragédia que foi apontada como a maior falha da comunicação científica, dando origem ao título do editorial que também chama a atenção para o papel do cientista na sociedade.

Sobre o impacto da Internet no jornalismo, o editor do Electronic Journal of Communication constata, em artigo, que a interação desse meio de comunicação com a tecnologia nunca foi tão dramática quanto à emergência da Internet como um meio de comunicação que se expandiu nos anos 90 .

Outros aspectos do jornalismo sofreram impacto com a emergência da Internet, como novos meios de publicação, ferramentas de reportagem e focos para educação do jornalismo. Além disso, a Internet tem 
provocado novas questões sobre responsabilidades sociais dos jornalistas para informar ao público, assim como a prática do jornalismo ético (King, 1997).

Não devemos ignorar que um número crescente de revistas de divulgação científica existentes no mercado, com respectivos sites na Internet, (MacedoRouet, 2002) ${ }^{9}$, pode ser considerado um indicador do interesse em resultados de pesquisas por leitores fora dos muros acadêmicos, ou público leigo. Esses leitores, ou usuários dessa informação ou conhecimento, interessados em resultados de pesquisas, compõem um segmento de público motivado para informações de ciência, assim definidos e identificados como o públicoalvo da divulgação científica.

Vale retomar o estudo de Hernandez Canãdas (1987, p. 14) sobre as revistas Ciência Hoje e Ciência e Cultura, em cuja análise de características a autora ora os identifica como periódico científico, ora como periódico de divulgação científica. Por outro lado, a ausência de precisão quanto ao conceito de revista de divulgação ou de comunicação científica, em geral, e pelos órgãos governamentais, inclusive, também corrobora essa argumentação. De 114 registros de periódicos, entre jornais e revistas de divulgação científica nacionais e estrangeiros, provenientes de levantamento realizado por Ramos (1992) junto à Biblioteca Nacional, cerca de 40 (nacionais e estrangeiros) podem ser classificados tanto como periódicos científicos, quanto como periódicos de divulgação científica.

É interessante observar que, no âmbito da própria comunidade científica, existe a preocupação em aproximar as áreas de comunicação e divulgação científica, como observamos na prática de algumas associações científicas. A IFSE - International Federation of Scientific Editors ${ }^{10}$ tem sido categórica em demonstrar, nos congressos internacionais que promove, a preocupação com a importância da divulgação científica não apenas como fator determinante para a popularização da ciência e da tecnologia, mas também como instrumento de legitimação da área e de maior conscientização da população para as questões da ciência. As palestras de sua Presidente, Miriam Balabam, e comunicações de membros da comunidade científica são incentivadas nesses encontros. Em âmbito nacional, a ABEC - Associação Brasileira de Editores Científicos -, além da proposta de discutir sua temática principal e buscar soluções para os problemas dos editores científicos, em seus congressos e encontros tem demonstrado preocupação crescente com a divulgação científica. A intenção de juntar essas discussões vemse definindo com mais precisão nos encontros da Associação por meio de sessão de posters sobre o tema.

As considerações feitas até aqui, assim como as próximas, apontam para a existência de um público internauta curioso por informações de e sobre ciência, que se sobrepõe ao público-alvo da divulgação científica.

Mostafá e Terra (2000) abordam as mudanças ocorridas na comunicação científica e a proximidade da ciência com o público, adotando idéias de Lèvy quanto à abrangência das comunidades virtuais e o poder de comunicação on-line, quando as cartas científicas do século 17 transformaram-se nas listas de discussão do século 21, onde tudo se discute (Lévy, 1993 apud Mostafá; Terra, 2000).

No exterior, a pesquisa conduzida pela Escola de Ciência da Informação da Universidade de Tenessee, por Carol Tenopir e Donald King (2000), sobre aspectos econômicos, contendo dados de uso das revistas científicas, revela, entre outras informações, que cientistas não lêem revistas científicas, dando preferência à rede de comunicação informal entre pares, rede que, atualmente, inclui o correio eletrônico. Esse dado remetenos à questão do acesso. Segundo informações disponibilizadas por Global Internet Statistics, em 2004 - Brasil, juntamente com outras comunidades de língua portuguesa, representava apenas 3,1\% da população mundial conectada à Internet. Em contrapartida, a população de língua inglesa participava com 35,2\% (Global Internet Statistics, 2004).

Estamos falando, entretanto, de aproximadamente 10 anos de tecnologia de redes e uso da Internet, e é natural que os números reflitam, de maneira geral, o nível de desenvolvimento desses países. 0 mundo virtual, porém, é ilimitado e a tecnologia de redes irreversível, estando em franca evolução o número de conexões da população mundial. Mesmo assim,

\footnotetext{
9 Análise de 41 títulos de revistas de divulgação cientifica vendidas em bancas no Brasil e em vários países e seus respectivos sites (Macedo; Rouet, 2002).

10 IFSE-08. $8^{a}$ Conferência da International Federation Scientific Editors - Barcelona, ES, 1995; IFSE-10. 10 Conferência da International Federation Scientific Editors - Rio de Janeiro, Brasil, 2000.
} 
ainda é prematuro afirmar se o número de conexões on-line perpetua ou não o modelo econômico que impõe restrições ao acesso. De acordo com a PNAD Pesquisa Nacional por Amostra de Domicílio - de 2002, do IBGE - Instituto Brasileiro de Geografia e Estatística -, em 2001 eram 12\% dos domicílios com computador (IBGE/PNAD, 2002). Ainda segundo dados da PNAD de 2005, os municípios com microcomputador com acesso à Internet representavam 13,7\%, porém, com faixa salarial acima de cinco salários mínimos, o percentual de pessoas que acessam a Internet representa $69,5 \%$ (IBGE/PNAD, 2005).

\section{UMA NOVA COMUNIDADE?}

Seja pelas constatações de fatos ocorridos, ou por resultados de pesquisa, podemos afirmar que já se evidenciam algumas alterações nas características e padrões da comunicação científica a partir da comunicação por meio das TICs. Essas modificações reforçam a hipótese aqui apresentada de aproximação entre a comunicação e a divulgação científica, como entendidas neste texto, especialmente na relação com o seu público, considerando, agora, que ele é percebido com novas dimensões, conformando-se ou formandose em novos contornos, proporcionado pelo alcance das TICs, que permitem percorrer, em fração de segundos, distâncias jamais imaginadas até bem recentemente. Também as TICs são responsáveis pelo considerável aumento do fluxo de informações para novos territórios, em campos de conhecimento diversificados, de múltiplos interesses e de acesso livre.

Dessa forma, configura-se um novo espaço (ciberespaço) com uma grande quantidade de informação de ciência disponibilizada na Internet, gerada pelos produtores de comunicação e de divulgação científica, seja comunicação por correio eletrônico, salas ou grupos de discussão, ou pelos próprios periódicos científicos, "nascidos" no meio virtual, ou mesmo com suas versões eletrônicas. Toda essa informação de acesso livre está à mercê dos sistemas de engenharia de busca da Internet para atender a todos que por ela navegam à procura de informações de ciência. Assim, temos que o acesso à rede constitui elemento fundamental na formação de novas comunidades virtuais que, associado ao acesso livre a arquivos (Open Access Archives), aproximam públicos, formam comunidades constituídas por elementos já pertencentes a alguma comunidade científica, estabelecida ou não. Trata-se de comunidades que agregam membros de comunidade científica, mas também aqueles interessados em ciência, ou curiosos em soluções práticas.

O estudo já mencionado de Hert (1997), sobre a dinâmica social da construção do debate acadêmico on-line foi selecionado na literatura, para enfatizar o nosso ponto de vista. Esse autor traz-nos duas contribuições que abordam a construção social da comunicação científica e o conceito de comunidade no processo de transformação da informação em conhecimento público. No estudo sobre a construção social da comunicação científica, Hert sugere como um novo estilo de comunicação pode surgir e ser institucionalizado mediante o uso socializado do meio. Ou ainda, citando Orlikowski e Yates apud Hert, 1997: como um estilo preexistente é reproduzido por meio de uma nova mídia. Na investigação sobre o possível uso da metáfora "comunidade" nas interações eletrônicas, McLaughlin e Smith, também citado por Hert (1997), argumentam que a alta proporção de leitores que não se identificam, ou não enviam mensagens nos grupos de discussão, pode chegar a constituir uma comunidade. Os lurkers, assim denominados, seriam uma comunidade amorfa e, possivelmente, efêmera, advertem -, trazendo outra ordem de problemas a serem investigados, mas que corroboram a tese aqui apresentada.

À luz desses autores, e sob os aspectos da extensão, importância e envolvimento no debate eletrônico, convergimos nossa opinião com a de Hert (1997), ao evidenciar que o uso do correio eletrônico revelou a existência de uma comunidade científica mais larga, heterogênea, com opiniões divergentes, a qual é difícil de distinguir nas comunicações oficiais e nas conferências, ou em outras formas de comunicação de ciência. Essa comunidade, a nosso ver, é o embrião de uma nova forma de participação que se delineia a partir das TICs, na qual a divulgação e a comunicação científica se entrelaçam no compartilhamento dos mesmos interesses. 


\section{REFERÊNCIAS}

ALVAREZ, A.C. Medios de comunicacion digitales. Sala de Prensa: periódico on line, v.5, n.2, 2002. Disponível em: <http:// www.saladeprensa.org >. Acesso em: 30 set. 2003.

BERNAT, J. Comunicación digital: apuntes básicos, asignatura 2. Materiales del master en comunicación digital. Barcelona: 2002.

BUENO, W.C. Jornalismo científico no Brasil: os compromissos de uma prática dependente. 1985. f. Tese (Doutorado em Ciências da Comunicação) - Escola de Comunicação, Universidade de São Paulo, São Paulo, 1985.

BUSH, V. As we may think. The Atlantic Monthly, 1945.

CETTO, A.M. Has it lived up to its promise? In: ICSU - UNESCO INTERNATIONAL CONFERENCE ON ELECTRONIC PUBLISHING IN SCIENCE, 2., 2001. Proceedings... Disponivel em: <http://eos.wdcb.ru/eps2/eps02002/eps02002.htm? > . Acesso em: 18 out. 2003

FROTA-PESSOA, O.J.R. O divulgador da ciência. Ciência e Cultura, v.40, n.6, 1988.

GARVEY, W.D.; GRIFFITH, B.C. Communication, the essence of science, Apêndice A, B. In: GARVEY, W.D. Communication: the essence of science. Oxford: Pergamon Press, 1979. p.299. Disponível em: <http://global-reach.biz/globstats/evol.html>. Acesso em: jun.2007.

GONÇALVES, N.L. Divulgação científica. In: KREINZ, G.; PAVAN, C. (orgs.). A espiral em busca do infinito. São Paulo: Publicações NJR, 1998. p.65-79

HERNANDEZ CANÃDAS, P.L. Os periódicos Ciência Hoje e Ciência e Cultura e a divulgação científica no Brasil. 1987. $154 \mathrm{f}$. Dissertação (Mestrado em Ciência da Informação) - CNPq/IBICT, Escola de Comunicação, Universidade Federal do Rio de Janeiro, Rio de Janeiro, 1987.

HERT, P. Social dynamics of an on-Line scholarly debate. The Information Society: an International Journal, v. 13, n.4, p.329. 360, 1997.

IBGE - INSTITUTO BRASILEIRO DE GEOGRAFIA E ESTATÍSTICA. Pesquisa nacional por amostra de domicílios - PNAD 2002. Disponível em: <http://www.ibge.gov.br/home/estatistica/ populacao/trabalhoerendimento/pnad2002/default.shtm > . Acesso em: 10 out. 2003.

IBGE - INSTITUTO BRASILEIRO DE GEOGRAFIA E ESTATÍSTICA. Pesquisa nacional por amostra de domicílios - PNAD 2005. Disponível em:<http://www.ibge.gov.br/home/estatistica/ populacao/trabalhoerendimento/pnad2005/sintesepnad2005. pdf >. Acesso em: 1 jun. 2007.

KING, E. O impacto da Internet no jornalismo. Electronic Journal of Communication, v.7, n.2, 1997.
MACEDO-ROUET, M. Revistas de divulgação científica - do texto ao hipertexto, em busca do mapa das fontes. In: MASSARANI, L.; MOREIRA, I.; BRITO, F. (Org.). Ciência e público: caminhos da divulgação científica no Brasil. Rio de Janeiro: Casa da Ciência/ Universidade Federal do Rio de Janeiro, v. _, p. 185-202, 2002.

MASSARANI, L., MOREIRA, I., BRITO, F. (Orgs.). Ciência e públiCo: caminhos da divulgação científica no Brasil. Rio de Janeiro: Casa da Ciência/UFRJ, 2002. p. 185-202. Série Terra Incógnita.

MASSARANI, L. A divulgação científica no Rio de Janeiro: algumas reflexões sobre a década de 20. 1988. 136f. Dissertação (Mestrado em Ciência da Informação) - Instituto Brasileiro de Informação em Ciência e Tecnologia, IBICT, Rio de Janeiro, 1998.

MEADOWS. A. J. A comunicação científica. Brasília: Briquet de Lemos Livros, 1999. 268p.

MELO, J.M. Informação científica na imprensa brasileira: origem, fonte e autoria. Ciência da Informação, v. 16, n. 1 p. 13-9, 1987.

MOSTAFÁ, S.; TERRA, M. Das cartas iluministas às listas de discussão. DataGramaZero, v. 1, n.3, 2000. Disponível em: <http:/ /www.dgz.org.br>. Acesso em: out. 2003.

NELKIN, D. Selling science: how the press covers science and technology. New York: W.H. Freeman and Company, 1995.

NUNES, O. Divulgação científica e suas funções básicas. Revista Espiral, Placa, a.4, n.16, 2003. Disponível em: <http:// www.eca.usp.br/nucleos/nir/espiral/placal6.htm>. Acesso em: 16 maio 2004.

PINHEIRO, L.V.R. Comunidades científicas e infra-estrutura tecnológica no Brasil para uso de recursos eletrônicos de comunicação e informação na pesquisa. Ciência da Informação, v.32, n.3, p.62-73, 2003.

RAMOS, M.G. Divulgação de informação em Energia Nuclear: ideologia, discurso e linguagem. 1992. 132f. Dissertação (Mestrado) Escola de Comunicação, Universidade Federal do Rio de Janeiro, Rio de Janeiro, 1992.

REIS, J.; GONÇALVES, N.L. Divulgação científica e o ensino. In: KREINZ, G., PAVAN, C. (orgs.). Idealistas isolados. São Paulo: Publicações NJR, 1999. p.47-66.

REIS, J.; GONÇALVES, N.L. Veículos de divulgação cientííca. In: KREINZ, G., PAVAN, C. (orgs.). Os donos da paisagem. São Paulo: Publicações NJR, 2000. p.7-69.

RIEUSSETE-LEMARIÉ, P. Otlet's mundaneum and the international perspective in the history of documentation and information science. Journal of the American Society for Information Science, v.48, n.4, 1997.

SCHWEIG, E.S.; GOMBERG, J.; BODIN, P.; PATTERSON, G.; DAVIS, $S$. The internet: shaking up scientific communication. 
Nature web matters. Disponível em: <http://www.nature.com/ nature/webmatters/equake>. Acesso em: out. 2003.

SCIDEV.net. Tsunami disaster: a failure in science communication. Editorial. 17 de janeiro, 2005. Disponível em: <http://www.scidev. net/Editorials/index.cfm?fuseaction= readEditorials\&itemid $=143$ \&language $=1>$. Acesso em: jan. 2005.

SANTOS, B.S. Da sociologia da ciência à política científica. Revista Critica de Ciências Sociais, n. 1, 1978. Disponível em: $<$ http://www.ces.fe.uc.pt/publicacoes/rccs/001/001_1.php>. Acesso em: 17 jul. 2005.
SOUZA, J.B. Teatro grego: tragédia \& comédia. Petropólis: Vozes, 1985.

TENOPIR, C.; KING, D. O uso e o valor dos periódicos científicos. In: INTERNATIONAL CONFERENCE OF SCIENCE EDITORS, 10., 2000, Rio de Janeiro. Proceedings... Rio de Janeiro, 2000.

ZIMAN, J.M. Conhecimento público. Belo Horizonte: Itatiaia, $1979.167 \mathrm{p}$. 
